\title{
When Organizational Identification Elicits Moral Decision- Making: A Matter of the Right Climate
}

\author{
Suzanne van Gils ${ }^{1} \cdot$ Michael A. Hogg $^{2} \cdot$ Niels Van Quaquebeke ${ }^{3} \cdot$ Daan van Knippenberg $^{4}$
}

Received: 10 November 2014 / Accepted: 16 July 2015/Published online: 6 August 2015

(c) The Author(s) 2015. This article is published with open access at Springerlink.com

\begin{abstract}
To advance current knowledge on ethical decision-making in organizations, we integrate two perspectives that have thus far developed independently: the organizational identification perspective and the ethical climate perspective. We illustrate the interaction between these perspectives in two studies (Study $1, N=144$, US sample; and Study 2, $N=356$, UK sample), in which we presented participants with moral business dilemmas. Specifically, we found that organizational identification increased moral decision-making only when the organization's climate was perceived to be ethical. In addition, we disentangle this effect in Study 2 from participants' moral identity. We argue that the interactive influence of organizational identification and ethical climate, rather than the independent influence of either of these perspectives, is crucial for understanding moral decision-making in organizations.
\end{abstract}

Keywords Organizational identification - Ethical climate $\cdot$ Moral decision-making $\cdot$ Moral identity

Suzanne van Gils

suzanne.vangils@maastrichtuniversity.nl

1 Department of Work and Social Psychology, Faculty of Psychology and Neuroscience, Maastricht University, PO Box 616, 6200 MD Maastricht, The Netherlands

2 School of Behavioral and Organizational Sciences, Claremont Graduate University, Claremont, CA, USA

3 Kühne Logistics University, Hamburg (DE), Germany

4 Department of Personnel and Organization Management, Rotterdam School of Management, Erasmus University, Rotterdam, The Netherlands
Research has attempted to explain ethical behavior in organizations from a variety of perspectives over the past decades (Treviño et al. 2006). In the literature on ethical behavior, there is a tendency to focus on either intrapersonal factors (Kohlberg 1981; Tenbrunsel and SmithCrowe 2008; Treviño 1986) or factors of the organization (Treviño and Weaver 2001; Victor and Cullen 1988). However, despite an abundant literature that states that behavior is the result of a person-situation interaction (e.g., Tett and Burnett 2003; Trevino 1986), insights into the relationship of the person with the organization as antecedent of moral behavior in organizations have remained underdeveloped. Only few papers have focused on the interaction between the organizational climate and the extent to which a person is willing to identify with the organization. In the current paper, we focus on this interaction rationale to provide new insights into moral decision-making in organizations. In particular, we focus on how the interaction between individuals' organizational identification and the perceived ethical climate of the organization affects employee moral decision-making.

Many different definitions exist with regard to what moral behavior in organizations or moral decision-making is, both within the field of organizational behavior (Eisenbeiss 2012; Graham et al. 2012; Rai and Fiske 2012) and between different disciplines of research (e.g., Jones 1995). Each of these definitions has its consequences for the boundaries and operationalizations of concepts in the research at hand. In the current study, we have chosen a commonly shared definition in the field of organizational behavior: "Morality is an interlocking set of values, practices, institutions, and evolved psychological mechanisms that work together to suppress or regulate selfishness and make social life possible" (Haidt, 2008, p. 70). In line with this definition, this study operationalizes moral decisions as 
those decisions that focus on the best outcome for the majority of people involved. Given the amount of available definitions and perspectives (Graham et al. 2012; Haidt 2008; Rai and Fiske 2012), providing a perspective that covers all possible moral perspectives is beyond the scope of our research.

Although the literature studies on organizational identification and ethical climate each provide some information on moral decision-making, we argue that only the combination of both perspectives provides a complete picture. The topics of identification and climate have been discussed together before; there has been some research that discusses how specific climates can increase organizational identification (Riketta 2005; van Dick et al. 2004), and much of the research on organizational identification discusses how identification relates to the adherence of group norms (Hogg and Hains 1996; Terry and Hogg 1996). However, despite the potential that is hidden when considering effects of each of these perspectives that are contingent on the other perspective, we are not aware of any research discussing the interaction between these two perspectives.

The literature on organizational identification has informed a wide variety of topics in the organizational literature (Riketta 2005; van Knippenberg and Hogg 2003; Van Knippenberg et al. 2004). One of the key insights of this research is that organizational identification motivates individuals to work in the service of organizational interests and to conform to organizational norms (Ashforth and Mael 1989; Dutton et al. 1994). This has recently led researchers to explore the notion that organizational identification also motivates moral behavior in organizations (Van Gils et al. 2010; Walumbwa et al. 2011). In counterpoint to this notion, however, recent research showed that organizational identification can also be associated with unethical behavior if it benefits the company (Umphress et al. 2010; Umphress and Bingham 2011). Thus, research about organizational identification provides insight into employees' commitment to show pro-organizational behavior, but should be enriched by information about norms in order to define the morality of such behavior.

Another perspective for ethical work behavior resides in the literature on ethical climate (Cullen et al. 1993; Martin and Cullen 2006). The concept of climate pertains to people's perception of "the way we do things around here," and in that sense has not only a descriptive but also a normative, prescriptive function-it is informative of the kinds of behaviors and attitudes that are expected and appreciated. When referring to the moral standards of behavior, one may thus speak of an ethical climate (Kuenzi and Schminke 2009). Such climate has been found to be positively related to organizational commitment (Cullen et al. 2003), job satisfaction (Deshpande 1996), and wellbeing (Martin and Cullen 2006), and negatively to deviant behaviors (Mayer et al. 2010; Peterson 2002; Wimbush et al. 1997). Despite these insights, organizational climate theory does not provide an explanation why employees would adhere to ethical standards in the organization; ethical climate may capture moral standards, but this in and of itself may not explain why an individual member of the organization would adhere to these standards. The ethical climate perspective thus needs to be extended with insights into employee commitment in order to provide an adequate explanation for moral decision-making.

In short, both perspectives, organizational identification and ethical climate, are essential to explain when and why moral behavior occurs in organizations. The main contribution of the literature on organizational identification lies in providing an understanding of what motivates individuals to pursue the organization's interest and adhere to organizational standards, whereas the literature on ethical climate captures the content of these standards that would motivate moral behavior. We propose a new way to integrate these two streams of research; via their interaction, such that organizational identification motivates moral behavior to the extent that there is an ethical climate in the organization. This integration is important to our understanding of moral decision-making because it brings together the perspective on perceptions of the organization's ethical standards and the perspective on the psychology of organizational membership that captures individual's internalization of such standards for a fuller appreciation of how the experience of organizational membership may motivate employee moral decisionmaking.

\section{Organizational Identification}

Research on organizational identification has informed numerous studies of organizational behavior (Riketta and van Dick 2005). Most of this research builds on Social Identity Theory (Abrams and Hogg 1990, 2010; Tajfel and Turner 1979) and the closely related Self-Categorization Theory (Turner et al. 1987)—see Abrams and Hogg (2010) for a recent overview. Social Identity Theory maintains that people have knowledge about themselves as members of social groups, which induces a feeling of belonging to one's own group, the ingroup, as well as an ethnocentric perception that the ingroup is superior to relevant other groups (outgroups). Self-Categorization Theory specifies the cognitive process taking place when people identify with a group. People cognitively represent social groups as prototypes that capture attitudinal and behavioral similarities within the group and accentuate differences between 
groups. The process of categorizing oneself or others as a members of a group depersonalizes perception so that self and others are no longer represented as unique individuals but as embodiments of the relevant group prototype. Categorization of self generates a feeling of group identification and assimilates self-perception and behavior to the group's prototype-it leads to group normative behavior (See Abrams and Hogg 1990; Hogg and Smith 2007).

Extending these theories to the domain of organizations (Ashforth and Mael 1989; Hogg and Terry 2000), organizational identification entails a feeling of belongingness or oneness with the organization. When organizational identification is high, the organization is an important part of the person's self-concept. High organizational identification makes employees derive a sense of self-definition from the group, view their fate as intertwined with the fate of the organization, and experience the organization's successes and failures as their own. Based on this, employees show stronger commitment to and support for the organization (Hogg and Terry 2000; Mael and Ashforth 1992), and display behavior that supports the organization (De Cremer et al. 2006; Van Dick et al. 2007).

When identifying with a certain group, group norms become prescriptive and descriptive for people's behavior (Terry and Hogg 1996). High identifiers display less norm incongruent behavior than low identifiers. Importantly, identification leads to an internalization of group norms such that the behavior is contingent on the salience of the group identity rather than the immediate context (Terry and Hogg 1996; Wellen et al. 1998). Thus, organizational identification may be associated with employee adherence to group norms and behaviors that benefit the collective (De Cremer et al. 2008; De Cremer and van Knippenberg 2004).

These studies, however, show that even when individuals are motivated to serve the organization, this serving behavior does not have to be moral per se. In addition, although the behavior might be moral according to one set of moral standards, it does not have to be moral according to all moral perspectives (Giessner and Van Quaquebeke 2010; Haidt et al. 2009; Rai and Fiske 2012). Indeed, even though some research has suggested that organizational identification is an important influence on moral behavior in organizations (van Gils et al. 2010; Walumbwa et al. 2011), organizational identification can also increase unethical behavior if it benefits the company (Umphress et al. 2010; Umphress and Bingham 2011). Moreover, individuals can have different identities, which, depending on their salience, determine which norms they adhere to (Hogg and Terry 2000; and see Leavitt and Reynolds 2012 for an example of the effect of competing identities). Furthermore, the norms in a group might be amoral and not concern aspects that directly concern moral behavior-in which case identification and norm adherence will not result in moral behavior. Thus, an analysis in terms of identification needs additional information about the organizational norms in order to account for moral behavior in organizations. This, we propose, is where ethical climate comes in.

\section{Ethical Climate}

A second perspective on moral behavior in organizations resides in the literature on ethical climate (Cullen et al. 1993; Martin and Cullen 2006; Mayer et al. 2010). The prevalence of moral norms in organizations, and the specific behavior prescribed by these norms, is captured by the concept of ethical climate (Kuenzi and Schminke 2009; Victor and Cullen 1988). Research on organizational work climates in general defines climate as a set of shared perceptions regarding the policies, practices, and procedures that an organization rewards, supports, and expects (Schneider 1990). Organizational climate can focus on different aspects of organizational behavior and can thus have a moral as well as an amoral focus (Tenbrunsel and Messick 1999). In the case of ethical climate, these policies, practices, and procedures prescribe the expected moral behavior within the organization (Kish-Gephart et al. 2010; Kuenzi and Schminke 2009).

Building on early theories of moral development (Kohlberg 1981), research investigating ethical climate has defined it in terms of whether self-interest, collective interest, or universal norms are the point of reference when making moral decisions (Victor and Cullen 1988). Importantly, the organizational climates that qualify as highly ethical have aspects that are shared as being moral by multiple perspectives (See Graham et al. 2012 for a discussion of similarities and differences across moral perspectives). Collectively, oriented climates relate to higher levels of organizational commitment, thereby illustrating that the climate serves as a behavioral norm for pro-social organizational behavior (Cullen et al. 2003), helping behavior (Kalshoven and Boon 2012), ethical judgments (Barnett and Vaicys 2000), and managerial moral decisions (Elm and Nichols 1993). Furthermore, ethical climate has been related to reductions in deviant behavior by employees (Mayer et al. 2010; Peterson 2002; Wimbush et al. 1997).

Although this research provides insights into the antecedents and outcomes of ethical climate, insights into when an ethical climate yields the results for organizations depend on a clear picture of when employees adhere to the ethical climate in the organization. However, current theorizing cannot explain why ethical climate by itself should be related to moral behavior (Mayer et al. 2009). Thus, the 
ethical climate perspective should be enriched with insights into follower commitment to accurately predict moral decision-making at work.

\section{Organizational Identification, Ethical Climate, and Moral Decision-Making}

Our aim in the present article is to advance knowledge about moral decision-making in organizations by integrating the two perspectives discussed above: the organizational identification perspective and the ethical climate perspective. While the organizational identification perspective mainly provides insights into the motivational aspects adherence to organizational norms (De Cremer et al. 2008; Hogg and Hains 1996; van Knippenberg and Hogg 2003), the ethical climate perspective shows how employees can use the organization's moral norms as a guideline for moral behavior (Kuenzi and Schminke 2009). Through integration, we enrich and develop the two perspectives and provide a more complete view on the dynamics underlying moral decision-making in organizations.

We argue that the interplay between the employee's identification with the organization and the ethical climate has a strong influence on employee moral decision-making. In this decision-making process, organizational identification serves as a motivating factor for adherence to organizational norms. According to Self-Categorization Theory (Hogg and Terry 2000; Turner et al. 1987), this collectiveoriented behavior is based on the cognitive assimilation of self to the group prototype evoked by organizational identification, which in turn increases willingness to comply with organizational norms (Terry and Hogg 1996). As highly identifying employees assimilate self to the organization, they should be particularly motivated to adhere to organizational norms, because they want to promote the organization (Hogg and Hains 1996; Riketta 2005) and because group interests and self-interests are aligned (Vadera and Pratt 2012).

The role of ethical climate is to provide detailed information that can be used as a guideline for appropriate behavior. Specifically, we suggest that as part of high identifiers' effort to assimilate to the group prototype, they will also be more actively searching for information about the prototypical behavior that is desired by the organization. This information is contained in the organization's ethical climate, which provides employees with information on desired policies, practices, and procedures (Martin and Cullen 2006; Victor and Cullen 1988). Ethical climate fosters moral judgment and helps employees decide on adequate behavior. This information is important for highly identifying members of the organization because it provides them with guidelines to express their commitment to the organization in a way that is appreciated and will help reinforce their position within it. In contrast, less identifying employees do not experience a sense of belonging to the organization and therefore will not react as strongly to the organizational climate.

Hypothesis Organizational identification has a stronger, positive relationship with moral decision-making when organizational climate is perceived to be ethical than when it is not.

\section{Study 1}

\section{Method}

\section{Sample}

Participants were 162 members of the US crowdsourcing website Mturk.com. A recent study confirms the quality of data collected in this way (Buhrmester et al. 2011). All participants took part on a voluntarily basis in return for a small reward. Of these participants 17 were excluded because they either indicated that they did not want their results to be used in our research $(N=8)$ or their responses to our open questions consisted either of non-words or random phrases that did not answer the question $(N=9)$. All participants were US citizens, and were either fulltime (72\%) or part-time employed $(27 \%)$. The average age was 33 years $(\mathrm{SD}=10.25)$ and $55 \%$ of participants were male. Participants' occupied various positions in their organizations, $28 \%$ were lower managers, $14 \%$ were middle managers, $6 \%$ were top managers, and $52 \%$ indicated that they were not currently supervising any employees. Participants had worked on average for 5.1 years for their organizations $(\mathrm{SD}=5.93)$.

\section{Measures}

Identification was measured with Mael and Ashforth's (1992) six-item scale, an example item is "when someone criticizes my organization, it feels like a personal insult," 1 disagree very strongly, 7 agree very strongly, $\alpha=0.91$.

Ethical climate was measured with six items representing the contrast between self-interested and benevolent ethical climates (Arnaud 2010; Victor and Cullen 1988). ${ }^{1}$

\footnotetext{
${ }^{1}$ We included Arnaud (2010)'s full scale in our research. This scale contains 18 items and was designed to have six sub-dimensions: Ethical climate sensitivity-moral awareness, sensitivity-empathic concern, individual judgment, collective judgment, motivation, and collective moral character. Exploratory factor analysis did not yield this structure in either Study 1 or Study 2. Confirmatory factor
} 
Example items are "people in my department are mostly out for themselves" (reverse coded), and "people in my department have a strong sense of responsibility to society and humanity," 1 disagree strongly, 7 agree strongly, $\alpha=0.87$. Ethical climate is, to some extent, a perceptual construct (Schneider and Reichers 1983). As our model is based on the assumption that the individual deduces norms to guide moral behavior from his or her perception of the climate, a self-report measure seemed to be the most appropriate measure.

Moral decision-making was measured by presenting participants with three business dilemmas (see Appendix). These dilemmas were comparable to dilemmas used in earlier studies (e.g., Loviscky et al. 2007; Zhong et al. 2010), and focused on normatively appropriate behavior in the organizational context. The first scenario described a dilemma in which participants had to decide whether to devote time to involving their team members in decisionmaking. The second scenario described a dilemma in which participants had to decide whether to reprimand an employee who was also a personal friend for violating the company's rules. The last scenario asked participants whether they would follow the suggestion of their manager to compromise the quality of their work in order to reach deadlines. After each dilemma, participants were asked to indicate their decision on a 7 point scale, 1 absolutely not, 7 absolutely. In addition, they were asked to provide a short explanation for their decision. These dilemmas each measure a different aspect of moral behavior in organizations (i.e., a formative design). These include moral behavior towards subordinates, co-workers, or in response to one's superior. They accumulate in an overall score for moral decision-making. Please note that as part of that design, assumptions about the necessity for strong inter-correlations among the scale items are relaxed even though the item average is used as our outcome variable (for discussions on formative vs reflective scores see Podsakoff et al. 2006; Podsakoff et al. 2003a).

\section{Results}

Means, standard deviations, scale reliabilities, and correlations for all variables are reported in Table 1.

To test our hypothesis, we conducted a stepwise linear multiple regression analysis. All regression coefficients are reported in Table 2. In the first step, we regressed moral

Footnote 1 continued

analyses did not show an adequate fit for a six factor model or a four factor model grouping the sensitivity and judgment subscales together. Based on these findings, we decided to only use the items related to moral judgment because (a) these are most closely related to our definition of morality and (b) the items were found to have a consistent factor structure. decision-making onto identification and ethical climate. These variables significantly influenced moral decisionmaking, $F(2,142)=7.60, p=0.01$. We found a significant main effect for ethical climate, $\beta=0.23$, $t(142)=2.93, p<0.01$, but not for organizational identification, $\beta=0.07, t(142)=0.89$, ns. In step 2 , we added the interaction, which also significantly influenced moral decision-making, $\quad F(3, \quad 141)=6.81, \quad p<0.01, \quad$ and explained additional variance in our model $\Delta R^{2}=0.03$, $F$ Change $(1,141)=4.83, p=0.03$. This finding confirmed the hypothesized interaction effect between identification and ethical climate on moral decision-making, $\beta=0.18, t(141)=2.20, p=0.03$. This interaction effect is displayed in Fig. 1.

Various demographic variables have been related to moral decision-making in other literature, for example, age and education have been related to moral development (Ford and Richardson 1994; Kohlberg 1981), women have been reported to make more communal decisions than men (Ford and Richardson 1994), and responsibility for a larger amount of people increases moral decision-making as well (Jones 1991). As these demographics have been found to influence moral decisions in other studies and thus might confound our results (Spector and Brannick 2011), we included them in the third step of our analysis. Despite the fact that extra variance was explained, $\Delta R^{2}=0.10$, $F$ Change $(4,137)=4.31, p<0.01$, the results for our model remained the same (see also Table 2).

Simple slopes analyses of the two-way interaction between organizational identification and ethical climate on moral decision-making (following recommendations by Aiken and West 1991) show that our results are in the hypothesized direction. Specifically, organizational identification increased moral decision-making when the organization was perceived to have an ethical climate, $\beta=0.20, t(137)=2.19, p=0.03$. For those in organizations without an ethical climate, however, organizational identification did not influence moral decision-making, $\beta=-0.01, t(137)=-0.14$, ns. (see Fig. 1). Taking organizational identification as the moderator, ethical climate significantly increased moral decision-making among those who identified strongly with their organization, $\beta=0.37, t(137)=3.28, p<0.01$, whereas for those who did not identify strongly ethical climate was not associated with moral decision-making, $\beta=0.06, t(137)=0.59$, ns. These results confirm our hypothesis that high organizational identification only translates into moral decisionmaking in the context of an ethical climate.

\section{Discussion Study 1}

The results of Study 1 confirm our hypothesis that organizational identification motivates moral decision-making 
Table 1 Means, standard deviations, and correlations for Study 1

\begin{tabular}{|c|c|c|c|c|c|c|c|c|}
\hline & $M$ & SD & 1 & 2 & 3 & 4 & 5 & 6 \\
\hline 1. Moral decision-making (scenario's) & 5.10 & 0.88 & - & & & & & \\
\hline 2. Organizational identification & 4.63 & 1.27 & $0.20 *$ & $(0.91)$ & & & & \\
\hline 3. Ethical climate & 4.39 & 1.23 & $0.30 * *$ & $0.47^{* *}$ & $(0.88)$ & & & \\
\hline \multicolumn{9}{|l|}{ Controls } \\
\hline 4. Gender & - & & 0.15 & 0.07 & 12 & - & & \\
\hline 5. Age & 33.23 & 10.25 & $0.34 * *$ & 0.07 & 0.13 & 0.04 & - & \\
\hline 6. Education & - & & 0.04 & 0.15 & 0.09 & -0.04 & 0.16 & - \\
\hline 7. Team size & 6.18 & 12.28 & $0.19 *$ & 0.08 & $0.17 *$ & -0.01 & -0.02 & -0.01 \\
\hline
\end{tabular}

$N=145$

$* p<0.05, * * p<0.01$, Cronbach's alpha for scales are displayed on the diagonal

Table 2 Overview of regression results for Study 1

\begin{tabular}{|c|c|c|c|c|c|c|c|c|c|}
\hline & \multicolumn{3}{|c|}{ Model 1} & \multicolumn{3}{|c|}{ Model 2} & \multicolumn{3}{|c|}{ Model 3} \\
\hline & $b$ & SE $b$ & $\beta$ & $b$ & $\mathrm{SE} b$ & $\beta$ & $b$ & SE $B$ & $\beta$ \\
\hline Organizational identification (ID) & 0.07 & 0.08 & 0.08 & 0.12 & 0.08 & 0.14 & 0.12 & 0.08 & 0.14 \\
\hline Ethical climate (EC) & 0.23 & 0.08 & $0.27 * *$ & 0.22 & 0.08 & $0.26 * *$ & 0.18 & 0.08 & $0.21 *$ \\
\hline $\mathrm{ID} \times \mathrm{EC}$ & & & & 0.13 & 0.06 & $0.18^{*}$ & 0.12 & 0.06 & $0.16^{*}$ \\
\hline \multicolumn{10}{|l|}{ Controls } \\
\hline Gender & & & & & & & 0.16 & 0.14 & 0.09 \\
\hline Age & & & & & & & 0.03 & 0.01 & $0.30^{* *}$ \\
\hline Education & & & & & & & -0.01 & 0.08 & -0.01 \\
\hline Position & & & & & & & -0.01 & 0.01 & 0.04 \\
\hline Adjusted $R^{2}$ & & 0.08 & & & 0.11 & & & 0.19 & \\
\hline$\Delta R^{2}$ & & $0.10^{* *}$ & & & $0.03 *$ & & & $0.10 * *$ & \\
\hline$F$ change & & 7.60 & & & 4.83 & & & 4.31 & \\
\hline df & & 143 & & & 141 & & & 137 & \\
\hline
\end{tabular}

$N=145$. Table presents $b$ coefficients, standard deviations, and standardized beta-coefficients

$* p<0.05, * * p<0.01$

when the organization is perceived to have an ethical climate but not if no ethical climate is perceived. These results illustrate the interplay between organizational identification and perceived ethical climate in the organization and thereby emphasize that for a positive relationship between organizational identification and moral behavior, the norms in the organization need to be moral.

\section{Study 2}

Literature on moral decision-making thus far mainly focuses on personality traits, such as moral development and social responsibility (Aquino and Douglas 2003; Kohlberg 1981; Tenbrunsel and Smith-Crowe 2008). Within this domain of research, specific attention has been paid to the individual's moral identity (Aquino and Reed
2002) which is the extent to which moral traits form an important aspect of a person's self-concept. Prior research has found that those with a moral identity make more moral decisions (Aquino and Douglas 2003; Aquino and Reed 2002) and are more likely to be ethical leaders (Mayer et al. 2012).

Although personality might have a strong influence on moral decision-making, moral behavior can also be influenced by the interplay between the person and the situation (Aquino et al. 2009). To show that the interactional effect of organizational identification and ethical climate is independent of employees' moral personality, we conducted a second study to replicate the effect found in Study 1 while controlling for individual differences in moral dispositions. Specifically, in Study 2, we controlled for moral identity in our analyses in order to show that the interaction of organizational identification and ethical 




Fig. 1 Interaction between organizational identification and ethical climate on moral decision-making, Study 1

climate predicts moral decision-making above and beyond the effects of individual moral characteristics.

\section{Method}

Sample

Participants in Study 2 were 467 members of a commercial online panel in the UK. Participants were invited through the panel website and participated voluntarily in return for a small reward. Of the original dataset, 108 participants were excluded because they either indicated that they did not want their results to be used in our research $(N=29)$ or their responses to our open questions asking for their motivation of their decisions consisted of non-words or phrases that did not answer the question $(N=79)$-this left 359 participants in our final dataset. All participants were either fulltime ( $81 \%)$ or part-time employed (19\%). The average age was 42 years $(S D=10.66)$, and 51 percent were male. Participants' occupied various positions in their organizations, $27 \%$ were lower managers, $26 \%$ were middle managers, and $12 \%$ were top managers, $23 \%$ indicated that they were not currently supervising any employees, $11 \%$ of the participants did not indicate their position. Participants worked on average for 8.5 years for their organizations $(\mathrm{SD}=8.02$ ). All participants completed the survey online, and procedures were almost identical to Study 1.

\section{Measures}

Organizational identification, $\alpha=0.91$, and ethical climate, $\alpha=0.84$, were measured with the same scales used in Study 1. In addition, moral decision-making was measured by presenting the participants with the same business dilemmas as used in Study 1.
Moral identity was measured with 9 items from Aquino and Reed's (2002) moral identity scale that asks participants to indicate the importance of possessing a number of moral characteristics. Example items are "Being someone who has these characteristics is an important part of who I am" and "I am actively involved in activities that communicate to others that I have these characteristics," 1 disagree strongly, 7 agree strongly, $\alpha=0.76$.

\section{Results}

Means, standard deviations, scale alphas, and correlations for all variables in Study 2 are reported in Table 3.

As in Study 1, we conducted a stepwise regression analysis which is reported in Table 4. As discussed above, research has found an effect of individual psychological variables related to morality (Aquino et al. 2009; Treviño et al. 2006); therefore, we controlled for moral identity in our analysis to show that the effects of organizational identification and ethical climate on moral decision-making hold above and beyond the effect of moral identity.

In the first step of our regression analysis (see Table 4 for all results), we regressed moral decision-making onto moral identity, organizational identification, and ethical climate. These variables significantly influenced moral decisionmaking, $F(3,353)=33.03, p<0.01$. Similar to Study 1 , the main effect for ethical climate was significant, $\beta=0.21$, $t(353)=4.22, p<0.001$, and the main effect for identification was not significant, $\beta=0.06, t(353)=1.13$, ns. We did find a main effect of moral identity on moral decisionmaking, $\beta=0.34, t(353)=6.72, p<0.001$.

In the second step, we entered the two-way interactions between organizational identification, ethical climate, and moral identity on moral decision-making, $F(6,350)=$ 21.23, $p<0.001$. Adding these variables explained additional variance, $\Delta R^{2}=0.05, F$ Change $(3,350)=7.59$, $p<0.001$. The analyses revealed the predicted interaction between organizational identification and ethical climate, $\beta=0.19, t(350)=3.92, p<0.001$. This confirms that the effect of organizational identification on moral decisionmaking depends on the presence of moral norms. This effect is displayed in Fig. 2.

Additional analyses exploring interactions between our key variables and moral identity showed that no interaction was found between organizational identification and moral identity, $\beta=0.05, t(350)=0.97$, ns.; thus, no differences in organizational identification were found between those with a strong or weaker moral identity. We did find an interaction between ethical climate and moral identity, $\beta=-0.20, t(350)=-3.68, p<0.001$, such that ethical climate had a positive effect on moral decision-making for those low in moral identity, whereas the moral decisionmaking for those high in moral identity was overall high 
Table 3 Means, standard deviations and correlations for Study 2

\begin{tabular}{|c|c|c|c|c|c|c|c|c|c|}
\hline & $M$ & $\mathrm{SD}$ & 1 & 2 & 3 & 4 & 5 & 6 & 7 \\
\hline 1. Moral decision-making (scenario's) & 5.58 & 0.89 & & & & & & & \\
\hline 2. Organizational identification & 5.07 & 1.24 & $0.25 * *$ & $(0.91)$ & & & & & \\
\hline 3. Ethical climate & 4.56 & 1.15 & $0.31 * *$ & $0.36^{* *}$ & $(0.84)$ & & & & \\
\hline 4. Moral identity & 5.40 & 0.86 & $0.41 * *$ & $0.34 * *$ & $0.22 * *$ & $(0.73)$ & & & \\
\hline \multicolumn{10}{|l|}{ Controls } \\
\hline 5. Gender & - & & 0.11 & -0.03 & $0.12 *$ & $0.21 * *$ & - & & \\
\hline 6. Age & 42.3 & 10.66 & $0.15 * *$ & $0.12 *$ & 0.07 & $0.18 * *$ & -0.07 & - & \\
\hline 7. Education & - & & 0.05 & -0.01 & -0.02 & 0.07 & 0.10 & $-0.11^{*}$ & - \\
\hline 8. Position & - & & 0.03 & 0.02 & 0.06 & 0.04 & 0.05 & $0.10^{*}$ & -0.03 \\
\hline
\end{tabular}

$N=357$

$* p<0.05, * * p<0.01$, Cronbach's alpha for scales are displayed on the diagonal

Table 4 Overview of regression results Study 2

\begin{tabular}{|c|c|c|c|c|c|c|c|c|c|c|c|c|}
\hline & \multicolumn{3}{|c|}{ Model 1} & \multicolumn{3}{|c|}{ Model 2} & \multicolumn{3}{|c|}{ Model 3} & \multicolumn{3}{|c|}{ Model 4} \\
\hline & $b$ & SE $b$ & $\beta$ & $b$ & SE $b$ & $\beta$ & $b$ & $\mathrm{SE} b$ & $\beta$ & $b$ & SE $b$ & $\beta$ \\
\hline Org.identification (ID) & 0.05 & 0.05 & 0.06 & 0.07 & 0.05 & 0.08 & 0.07 & 0.05 & 0.08 & 0.07 & 0.05 & 0.08 \\
\hline Ethical climate (EC) & 0.19 & 0.05 & $0.21 * *$ & 0.21 & 0.05 & $0.24 * *$ & 0.20 & 0.05 & $0.23 * *$ & 0.20 & 0.05 & $0.22 * *$ \\
\hline Moral identity (MI) & 0.30 & 0.05 & $0.34 * *$ & 0.28 & 0.04 & $0.32 * *$ & 0.27 & 0.05 & $0.31 * *$ & 0.26 & 0.05 & $0.29 * *$ \\
\hline $\mathrm{ID} \times \mathrm{EC}$ & & & & 0.14 & $\mathbf{0 . 0 3}$ & $0.19 * *$ & 0.14 & 0.04 & $0.19 * *$ & 0.14 & 0.03 & $0.19 * *$ \\
\hline $\mathrm{ID} \times \mathrm{MI}$ & & & & 0.04 & 0.04 & 0.05 & 0.04 & 0.04 & 0.05 & 0.04 & 0.04 & 0.05 \\
\hline $\mathrm{EC} \times \mathrm{MI}$ & & & & -0.18 & 0.05 & $-0.19 * *$ & -0.18 & 0.05 & $-0.20 * *$ & -0.17 & 0.05 & -0.19 \\
\hline $\mathrm{ID} \times \mathrm{EC} \times \mathrm{MI}$ & & & & & & & 0.02 & 0.04 & 0.03 & 0.03 & 0.04 & 0.04 \\
\hline Gender & & & & & & & & & & 0.04 & 0.09 & 0.02 \\
\hline Age & & & & & & & & & & 0.01 & 0.01 & 0.06 \\
\hline Education & & & & & & & & & & 0.02 & 0.03 & 0.04 \\
\hline Managerial position & & & & & & & & & & 0.01 & 0.01 & 0.02 \\
\hline Adjusted $R^{2}$ & $0.21 * *$ & $0.25^{* *}$ & $0.25 * *$ & 0.25 & & & & & & & & \\
\hline$\Delta R^{2}$ & & & & & $0.048 * *$ & & & 0.001 & & 0.005 & & \\
\hline$F$ change & & & & & 7.59 & & & 0.37 & & 0.65 & & \\
\hline $\mathrm{df}$ & & 353 & & & 350 & & & 349 & & 345 & & \\
\hline
\end{tabular}

$N=357$. Table presents $b$ coefficients, standard deviations, and standardized beta-coefficients

$* p<0.05, * * p<0.01$

and unaffected by ethical climate. This effect is displayed in Fig. 3.

To make sure that there was no confounding effect of moral identity, we included the three-way interaction between organizational identification, ethical climate, and moral identity in the third step of our analysis. As we suggest that organizational identification and moral identity influence moral decision-making in different ways, no significant results were expected for this interaction. Indeed, adding the three-way interaction did not explain additional variance, $\Delta R^{2}=0.001, F$ Change $(1,349)=0.37$, ns., and the interaction effect was not significant, $\beta=0.03$, $t(345)=0.70$, ns. Thus, although moral identity is important for moral decision-making, it does not influence the interplay between organizational identification and the organization's moral norms.

Finally, as explained in Study 1, in the last step we included age, gender, education, and managerial position as control variables. No significant changes in our results were found based on this analysis.

Simple slope analysis (Aiken and West 1991) provided further evidence for the replication of the effect found in 




Fig. 2 Interaction between organizational identification and ethical climate on moral decision-making, Study 2

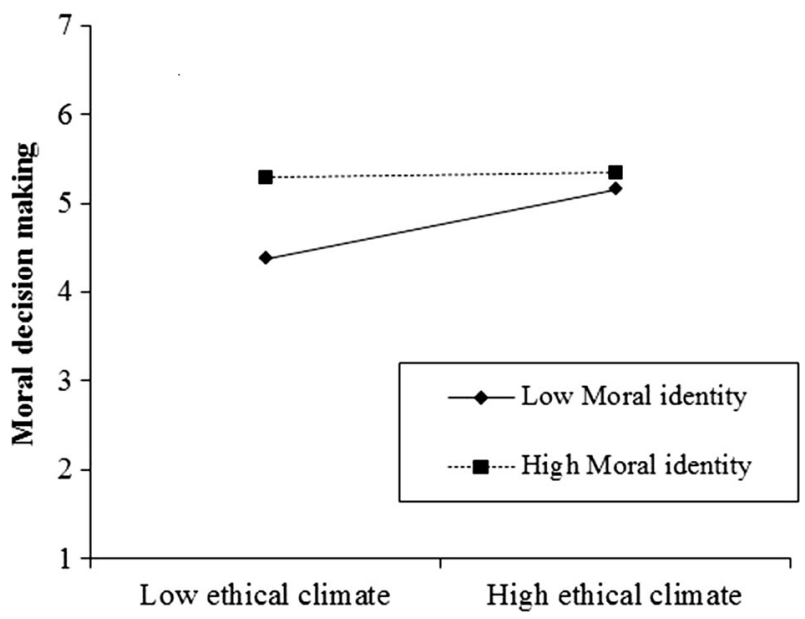

Fig. 3 Interaction between ethical climate and moral identity on moral decision-making, Study 2

Study 1. Specifically, those high in organizational identification show more moral decision-making when the ethical climate is strong, $\beta=0.18, t(347)=2.66, p<0.01$, while when the ethical climate was less salient no such relationship exists, $\beta=-0.05, t(347)=-0.85$, ns. Similar to Study 1, additional analyses showed that these effects are mainly driven by different effects for the presence or absence of an ethical climate for high organizational identifiers, $\beta=0.31, t(347)=5.00, p<0.01$. For those low in organizational identification, no such difference based on ethical climate existed, $\beta=0.08, t(347)=$ 1.25 , ns.

\section{Discussion Study 2}

The findings of Study 2 confirm our hypothesis that organizational identification is more strongly related to moral decision-making when the organization has an ethical climate. In addition, as in Study 1, we found that the results were based on different effects of the presence and absence of an ethical climate on the moral decision-making of high organizational identifiers. Importantly, additional analyses in this second study showed that organizational identification and ethical climate predicted moral decision-making above and beyond the effect of moral identity. As expected, although there was a main effect of moral identity on moral decision-making, and some significant two-way interactions including moral identity, there was no three-way interaction between moral identity, organizational identification, and ethical climate, and the two-way interaction between organizational identification and ethical climate remained significant.

\section{General Discussion}

The main aim of this study was to integrate two important theoretical perspectives that can inform moral decisionmaking in organizations: the organizational identification perspective and the ethical climate perspective, in order to better understand the processes leading to moral decisionmaking. In two studies, we provide first evidence that organizational identification is positively related to moral decision-making when the organization is perceived to have an ethical climate. Specifically, in assessing participants' responses to business dilemmas, we found in both studies that higher employee organizational identification increased moral decision-making in organizations with a perceived ethical climate, but not in organizations where no ethical climate was perceived. Put differently, we found that highly identifying employees in organizations with a perceived ethical climate showed more moral decisionmaking, whereas less identifying employees did not.

Additional analyses in Study 2 showed that the interaction between organizational identification and perceived ethical climate predicted moral decision-making above and beyond any direct association between moral identity (as an individual difference variable) and moral decisionmaking. This highlights that the relationship between the employee and the organization influences moral behavior above and beyond the effects of a moral personal identity.

\section{Theoretical Contribution}

The literature on organizational identification has discussed its relationship to pro-social (De Cremer et al. 2008; De Cremer and van Knippenberg 2005) and pro-organizational behavior (Ashforth and Mael 1989; Riketta 2005), and in a few studies has been related to ethical organizational behavior (Walumbwa et al. 2011). In the present paper, we 
extend this perspective by addressing the content of the norms that organizational identification motivates employees to adhere to, and by illustrating the importance of an ethical organizational climate to ensure moral decision-making in organizations.

In addition, our proposed integration of the organizational identification perspective and the ethical climate perspective enriches the literature on ethical climate by providing a theoretically sound framework for when and why employees would comply with the ethical norms of the organization. While research on ethical climate has not occupied a prominent position in the literature on moral behavior (Mayer et al. 2009), the current studies clearly illustrate its added value to derive a more specific explanation of moral decision-making in organizations. Integration of the two perspectives and exploring their interaction thus explains a larger proportion of the variance in moral decision-making. Importantly, the connection between the employee's identification and the aspects of the ethical climate in the organization that the employee identifies with (cf. Dick et al. 2004) may depend on the specific cognitive moral framework that the employee uses to interpret the situation (Graham et al. 2012; Haidt et al. 2009; Rai and Fiske 2012). However, regardless of the employees' private definition of morality and moral values, when the norms and regulations in an ethical climate are formulated broadly enough, each employee should be able to find a reflection of his or her personal values which can serve as a target for identification. Future research should investigate extensions of our findings, for example, whether ethical climate has a positive influence on the citizenship or performance of employees that identify more strongly, or whether intergroup management in organizations is easier if an ethical climate is present.

Furthermore, our analyses of the effects of moral identity in Study 2 show that while moral identity has its unique effect on moral decision-making, and those low in moral identity benefit from an ethical climate, moral identity does not affect the interactive effect of organizational identification and ethical climate on moral decision-making. This suggests that there may be two different ways to bring out moral decision-making, one through increasing organizational identification in the context of an ethical climate, and the other by increasing the salience of individual's moral identity. Thus, personality and the employee-organization relationship likely each have their unique effect on moral organizational behavior. Furthermore, these findings underline our suggestion that the results are independent of the employees' moral identity. Arguably, Aquino and Reed's (2002) conceptualization of a moral personality as being based on traits such as caring, generous, helpful, or honest might just represent one perspective on what a moral personality is (cf. Eisenbeiss 2012; Graham et al.
2011; Haidt et al. 2009; Rai and Fiske 2012). However, as it is impossible to cover all existing perspectives on morality, we have chosen to focus in our research on the common definitions in our field of research, which in turn correspond to our empirical operationalization. Future research should aim at exploring other perspectives on morality and their interrelationships with organizational climate in more depth.

Finally, our research emphasizes the importance of taking into account different levels of measurement and different organizational perspectives. Organizational climate and organizational identification are phenomena that operate both at the group- or organizational level and at the individual level. However, traditionally, research on organizational climate has focused more on organizationallevel processes (Kuenzi and Schminke 2009; Mayer et al. 2009), while research on organizational identification has focused more strongly at the individual level (Riketta and van Dick 2005; van Knippenberg and Hogg 2003). Potentially, our research findings can be expanded to an even more macro-level, allowing for an even more extensive integration of different perspectives. Such a macroperspective is, however, beyond the generalizations that can be drawn on the basis of our empirical findings.

\section{Managerial Implications}

The present research underlines the importance of organization wide training-or other measures to create an organizational ethical climate. However, subjecting people to ethical trainings and corporate town hall meetings may not be a sufficient strategy to improve moral conduct within the organization-it profits from additional organizational identification (Ashforth and Mael 1989; Dutton et al. 1994). While the one gives the direction, the other provides the fuel. Trainings and initiatives should thus follow this two-pronged strategy in order to truly have an impact on the behavior of employees. Indeed, we would warn practitioners to that it may be counter-productive to stage various ethics-focused events which at the same time may undermine the morale of employees by telling them off for their misconduct and threatening with insolvency should such behavior not be changed (cf. investment banks). While misconduct should in no way be condoned, its eradication should not throw the baby out with the bathwater. Rather, smarter strategies to align heightened identification together with a (new) ethical climate should be thought of. For instance, compliance officers may find it easier to proactively provide those who are highly identified with the organization with concrete guidelines for their behavior to ensure that they can lead the way as multipliers. Or initiatives might be developed how to increase organizational identification among those that an 
organization already deems (ethically) good citizens. Thus, there is a large role for HR practices as well as leadership to optimize the synchrony between the organizational climate and employee identification. Indeed, although discussing the influence of leadership on the ethical climate is beyond the scope of this paper, future research might explore the role of this antecedent to ethical climate (see Kuenzi and Schminke 2009 for an overview of antecedents and outcomes of ethical climate).

\section{Strengths and Limitations}

A limitation of our research is that the findings of both studies are based on data reported by the same source. Although self-report may be a relatively accurate way to assess deviant behavior because others do not have insights in all private behaviors of the focal employee, there remains a risk of same source bias in our single source approach (Podsakoff et al. 2003b). In this respect, it is important to note, however, that single source biases cannot account for interaction effects-indeed, if anything they lead to an underestimation of interactions (Evans 1985; McClelland and Judd 1993). Given that our conclusions revolve around interactions, the single source nature of the current studies should be somewhat less of a concern. Moreover, as the dependent measure of moral decision-making was measured through decision vignettes, the implied causal chain was supported. Even so, we readily acknowledge that future research employing multi-source set-ups may bolster the confidence in the current conclusions.

Secondly, we chose to investigate moral decision-making in our research within the context of the employee's behavior towards others (i.e., involving team members, cutting bonuses, maintaining quality). These behaviors match most closely to the self-interest versus benevolence dimension (Haidt 2008) that was central to our research. Future research could investigate the relationship between organizational identification and ethical climate on other types of counterproductive as well as positive moral behaviors.

\section{Conclusion}

When trying to explain moral decision-making in organizations, it is essential to consider the relationship between the person and the organization. In this respect, we present empirical support for organizational identification and perceived ethical climate to motivate moral decisions in concert. Specifically, we found that organizational identification is related to higher moral decision-making when the organization was perceived to have an ethical climate. Thereby, we show that considering both perspectives simultaneously provides a more detailed insight into moral decision-making. This research places recent scandals in context by suggesting that moral conduct in organizations may be a function of individual attachment to the organization as well as the organization's ethical climate.

Acknowledgments This research was sponsored by a research grant from the Erasmus Trustfund awarded to the first author.

Open Access This article is distributed under the terms of the Creative Commons Attribution 4.0 International License (http://creati vecommons.org/licenses/by/4.0/), which permits unrestricted use, distribution, and reproduction in any medium, provided you give appropriate credit to the original author(s) and the source, provide a link to the Creative Commons license, and indicate if changes were made.

\section{Appendix: Scenario's}

\section{Scenario 1}

Imagine receiving the following phone message from your colleague at the financial department-Please indicate your decision and shortly explain your reasons below.

I'm still looking at the company's budget for next year, and I need to get the estimated budget for your team. Some of the other VP's have started doing the budget with their team members. Although they believe it slows the process down (and takes up valuable time), they believe that it helps to develop the team members. So, I wanted to see if you will be working on your budget alone, or if you will be involving your team members in the process. What do you think?

I will involve my team members in this decision, even if it takes time.

\section{Scenario 2}

Imagine receiving the following phone message from one of your team members, who is also your personal friendPlease indicate your decision and shortly explain your reasons below.

I have heard that you need to cut my bonus based on the fact that I sometimes come in late or just stay for lunch somewhat longer than the others. You know my opinion about the strictness with which these rules are implemented in this company...). Anyway, I can really use the money and as we have been friends for years now, I just hope that you can give me a break.

I will cut the bonus, regardless of our friendship.

\section{Scenario 3}

Imagine receiving the following phone message from your senior manager-Please indicate your decision and shortly explain your reasons below. 
In response to your request for advice on how to meet all the deadlines coming up, my suggestion would be to just do whatever you need to do. The clients know us as a "total quality" organization and rarely complain about substandard work. Knowing you, you are probably worried about the effects on our reputation in the long run, but I would suggest to just leave that aside for now. I am confident that you and your team will manage to reach these deadlines.

I will sacrifice the quality of the work in order to reach the deadlines.

\section{References}

Abrams, D., \& Hogg, M. A. (1990). Social identification, selfcategorization and social influence. European Review of Social Psychology, 1(1), 195-228. doi:10.1080/14792779108401862.

Abrams, D., \& Hogg, M. A. (2010). Social identity and selfcategorization. In J. F. Dovidio, M. Hewstone, P. Glick, \& V. M. Esses (Eds.), The SAGE handbook of prejudice, stereotyping and discrimination (pp. 179-193). London: SAGE.

Aiken, L. S., \& West, S. G. (1991). Multiple regression: Testing and interpreting interactions. Newbury Park, CA: Sage.

Aquino, K. F., \& Douglas, S. (2003). Identity threat and antisocial behavior in organizations: The moderating effects of individual differences, aggressive modeling, and hierarchical status. Organizational Behavior and Human Decision Processes, 90(1), 195-208. Retrieved from http://www.sciencedirect.com/science/ article/B6WP2-47WD7TX-5/2/69aaa5ae30f99f01e9731fa8305e 8889

Aquino, K. F., Freeman, D., Reed, A., Lim, V. K. G., \& Felps, W. (2009). Testing a social-cognitive model of moral behavior: The interactive influence of situations and moral identity centrality. Journal of Personality and Social Psychology, 97(1), 123-141. doi:10.1037/a0015406.

Aquino, K. F., \& Reed, A, I. I. (2002). The self-importance of moral identity. Journal of Personality and Social Psychology, 83(6), 1423-1440. doi:10.1037/0022-3514.83.6.1423.

Arnaud, A. (2010). Conceptualizing and measuring ethical work climate. Business and Society, 49(2), 345-358. doi:10.1177/ 0007650310362865.

Ashforth, B. E., \& Mael, F. (1989). Social identity theory and the organization. Academy of Management Review, 14(1), 20-39. Retrieved from http://www.jstor.org/stable/258189

Barnett, T., \& Vaicys, C. (2000). The moderating effect of individuals' perceptions of ethical work climate on ethical judgments and behavioral intentions. Journal of Business Ethics, 27(4), 351-362. doi:10.1023/A:1006382407821.

Buhrmester, M., Kwang, T., \& Gosling, S. D. (2011). Amazon's Mechanical Turk. Perspectives on Psychological Science, 6(1), 3-5. doi:10.1177/1745691610393980.

Cullen, J. B., Parboteeah, K. P., \& Victor, B. (2003). The Effects of ethical climates on organizational commitment: A two-study analysis. Journal of Business Ethics, 46(2), 127-141. Retrieved from http://www.jstor.org/stable/25075095

Cullen, J. B., Victor, B., \& Bronson, J. W. (1993). The ethical climate questionnaire: An assessment of its development and validity. Psychological Reports, 73(2), 667-674. doi:10.2466/pr0.1993. 73.2.667.

De Cremer, D., \& van Knippenberg, D. (2004). Leader self-sacrifice and leadership effectiveness: The moderating role of leader selfconfidence. Organizational Behavior and Human Decision Processes, 95(2), 140-155. doi:10.1016/j.obhdp.2004.04.002.
De Cremer, D., \& van Knippenberg, D. (2005). Cooperation as a function of leader self-sacrifice, trust, and identification. Leadership and Organization Development Journal, 26(5), 355-370. doi:10.1108/01437730510607853.

De Cremer, D., van Knippenberg, D., van Dijk, E., \& van Leeuwen, E. (2008). Cooperating if one's goals are collective-based: Social identification effects in social dilemmas as a function of goal transformation. Journal of Applied Social Psychology, 38(6), 1562-1579. doi:10.1111/j.1559-1816.2008.00359.x.

De Cremer, D., van Knippenberg, D., van Dijke, M., \& Bos, A. E. R. (2006). Self-sacrificial leadership and follower self-esteem: When collective identification matters. Group Dynamics: Theory, Research, and Practice, 10(3), 233-245. doi:10.1037/1089-2699.10.3.233.

Deshpande, S. P. (1996). The impact of ethical climate types on facets of job satisfaction: An empirical investigation. Journal of Business Ethics, 15(6), 655-660. Retrieved from http://www. jstor.org/stable/25072791

Dick, R., Wagner, U., Stellmacher, J., \& Christ, O. (2004). The utility of a broader conceptualization of organizational identification: Which aspects really matter? Journal of Occupational and Organizational Psychology, 77(2), 171-191. doi:10.1348/ 096317904774202135.

Dutton, J. E., Dukerich, J. M., \& Harquail, C. V. (1994). Organizational images and member identification. Administrative Science Quarterly, 39(2), 239-263. Retrieved from http://www.jstor.org/ stable $/ 2393235$

Eisenbeiss, S. A. (2012). Re-thinking ethical leadership: An interdisciplinary integrative approach. Leadership Quarterly, 23(5), 791-808. doi:10.1016/j.leaqua.2012.03.001.

Elm, D. R., \& Nichols, M. L. (1993). An investigation of the moral reasoning of managers. Journal of Business Ethics, 12(11), 817-833. doi:10.1007/BF00871663.

Evans, M. G. (1985). A Monte Carlo study of the effects of correlated method variance in moderated multiple regression analysis. Organizational Behavior and Human Decision Processes, 36(3), 305-323. doi:10.1016/0749-5978(85)90002-0.

Ford, R. C., \& Richardson, W. D. (1994). Ethical decision making: A review of the empirical literature. Journal of Business Ethics, 13(3), 205-221. doi:10.1007/BF02074820.

Giessner, S. R., \& Van Quaquebeke, N. (2010). Using a relational models perspective to understand normatively appropriate conduct in ethical leadership. Journal of Business Ethics, 95, 43-55. doi:10.1007/s10551-011-0790-4.

Graham, J., Haidt, J., Koleva, S., Motyl, M., Iyer, R., Wojcik, S. P., \& Ditto, P. H. (2012). Moral foundations theory: The pragmatic validity of moral pluralism. Retrieved from http://papers.ssrn. com/abstract $=2184440$

Graham, J., Nosek, B. A, Haidt, J., Iyer, R., Koleva, S., \& Ditto, P. H. (2011). Mapping the moral domain. Journal of Personality and Social Psychology, 101(2), 366-85. Retrieved from http://www. pubmedcentral.nih.gov/articlerender.fcgi?artid=3116962\&tool= pmcentrez\&rendertype $=$ abstract

Haidt, J. (2008). Morality. Perspectives on Psychological Science, 3(1), 65-72. doi:10.1111/j.1745-6916.2008.00063.x.

Haidt, J., Graham, J., \& Joseph, C. (2009). Above and below left-right: Ideological narratives and moral foundations. Psychological Inquiry, 20(2-3), 110-119. doi:10.1080/10478400903028573.

Hogg, M. A., \& Hains, S. C. (1996). Intergroup Relations and Group Solidarity: Effects of Group Identification and Social Beliefs on Depersonalized Attraction. Journal of Personality and Social Psychology, 70(2), 295-309. Retrieved from http://ovidsp.ovid. com/ovidweb.cgi? $\mathrm{T}=\mathrm{JS} \& \mathrm{CSC}=\mathrm{Y} \& \mathrm{NEWS}=\mathrm{N} \& \mathrm{PAGE}=$ fulltext $\&$ $\mathrm{D}=$ ovftb\&AN=00005205-199602000-00008

Hogg, M. A., \& Smith, J. R. (2007). Attitudes in social context: A social identity perspective. European Review of Social Psychology, 18(1), 89-131. doi:10.1080/10463280701592070. 
Hogg, M. A., \& Terry, D. J. (2000). Social identity and selfcategorization processes in organizational contexts. Academy of Management Review, 25(1), 121-140. doi:10.5465/AMR.2000. 2791606.

Jones, T. M. (1991). Ethical decision making by individuals in organizations: An issue-contingent model. Academy of Management Review, 16(2), 366-395. Retrieved from http://www.jstor. org/stable/258867

Jones, T. M. (1995). Instrumental stakeholder theory: A synthesis of ethics and economics. Academy of Management Review, 20(2), 404-437. doi:10.5465/AMR.1995.9507312924.

Kalshoven, K., \& Boon, C. T. (2012). Ethical leadership, employee well-being, and helping: The moderating role of human resource management. Journal of Personnel Psychology, 11(1), 60-68. doi:10.1027/1866-5888/a000056.

Kish-Gephart, J. J., Harrison, D. A., \& Treviño, L. K. (2010). Bad apples, bad cases, and bad barrels: Meta-analytic evidence about sources of unethical decisions at work. Journal of Applied Psychology, 95(1), 1-31. Retrieved from http://ovidsp.ovid.com/ ovidweb.cgi?T $=\mathrm{JS} \& \mathrm{CSC}=\mathrm{Y} \& \mathrm{NEWS}=\mathrm{N} \& \mathrm{PAGE}=$ fulltext $\& \mathrm{D}=$ ovftk\&AN=00004565-201001000-00001

Kohlberg, L. (1981). Essays on Moral Development I: The Philosophy of Moral Development (Vol. 1). San Francisco, CA: Harper \& Row.

Kuenzi, M., \& Schminke, M. (2009). Assembling fragments into a lens: A review, critique, and proposed research agenda for the organizational work climate literature. Journal of Management, 35(3), 634-717. doi:10.1177/0149206308330559.

Leavitt, K., \& Reynolds, S. J. (2012). Different Hats, Different Obligations: Plural Occupational Identities and Situated Moral Judgments. Academy of Management Journal, 55(6), 1316-1334. Retrieved from http://amj.aom.org/content/55/6/1316.short

Loviscky, G. E., Treviño, L. K., \& Jacobs, R. R. (2007). Assessing managers' ethical decision-making: An objective measure of managerial moral judgment. Journal of Business Ethics, 73(3), 263-285.

Mael, F., \& Ashforth, B. E. (1992). Alumni and Their Alma Mater: A Partial Test of the Reformulated Model of Organizational Identification. Journal of Organizational Behavior, 13(2), 103-123. Retrieved from http://www.jstor.org/stable/2488176

Martin, K. D., \& Cullen, J. B. (2006). Continuities and extensions of ethical climate theory: A meta-analytic review. Journal of Business Ethics, 69(2), 175-194. doi:10.1007/s10551-006-9084-7.

Mayer, D. M., Aquino, K. F., Greenbaum, R. L., \& Kuenzi, M. (2012). Who displays ethical leadership and why does it matter? An examination of antecedents and consequences of ethical leadership. Academy of Management Journal, 55(1), 151-171. doi:10.5465/amj.2008.0276.

Mayer, D. M., Kuenzi, M., \& Greenbaum, R. L. (2009). Making ethical climate a mainstream management topic. In D. De Cremer (Ed.), Psychological perspectives on ethical behavior and decision making (pp. 181-213). Charlotte, NC: Information Age Publishing.

Mayer, D. M., Kuenzi, M., \& Greenbaum, R. L. (2010). Examining the link between ethical leadership and employee misconduct: The mediating role of ethical climate. Journal of Business Ethics, 95, 7-16. doi:10.1007/s10551-011-0794-0.

McClelland, G. H., \& Judd, C. M. (1993). Statistical difficulties of detecting interactions and moderator effects. Psychological Bulletin, 114(2), 376-390.

Peterson, D. K. (2002). The relationship between unethical behavior and the dimensions of the ethical climate questionnaire. Journal of Business Ethics, 41(4), 313-326. doi:10.1023/A:102124 3117958

Podsakoff, P. M., Mackenzie, S. B., Lee, J.-Y., \& Podsakoff, N. P. (2003a). Common method biases in behavioral research: A critical review of the literature and recommended remedies. Journal of Applied Psychology, 88(5), 879-903. doi:10.1037/ 0021-9010.88.5.879.

Podsakoff, P. M., MacKenzie, S. B., Podsakoff, N. P., \& Lee, J.-Y. (2003b). The mismeasure of man(agement) and its implications for leadership research. Leadership Quarterly, 14(6), 615-656. doi:10.1016/j.leaqua.2003.08.002.

Podsakoff, N. P., Shen, W., \& Podsakoff, P. M. (2006). The role of formative measurement models in strategic management research: Review, critique, and implications for future research. Research Methodology in Strategy and Management, 3, 197-252. doi:10.1016/S1479-8387(06)03008-6.

Rai, T. S., \& Fiske, A. P. (2012). Moral psychology is relationship regulation: Moral motives for unity, hierarchy, equality, and proportionality. Psychological Review, 23, 189-193. doi:10. 1037/a0021867.

Riketta, M. (2005). Organizational identification: A meta-analysis. Journal of Vocational Behavior, 66(2), 358-384. doi:10.1016/j. jvb.2004.05.005.

Riketta, M., \& van Dick, R. (2005). Foci of attachment in organizations: A meta-analytic comparison of the strength and correlates of workgroup versus organizational identification and commitment. Journal of Vocational Behavior, 67(3), 490-510. Retrieved from http://www.sciencedirect.com/science/article/pii/ S0001879104000867

Schneider, B. (1990). Organizational climate and culture. San Francisco, CA: Jossey-Bass.

Schneider, B., \& Reichers, A. E. (1983). On the etiology of climates. Personnel Psychology, 36(1), 19-39. doi:10.1111/j.1744-6570. 1983.tb00500.x.

Spector, P. E., \& Brannick, M. T. (2011). Methodological urban legends: The misuse of statistical control wariables. Organizational Research Methods, 14(2), 287-305. doi:10.1177/109442 8110369842.

Tajfel, H., \& Turner, N. (1979). An integrative theory of intergroup confict. In W. G. Austin \& S. Worcel (Eds.), The social psychology of intergroup relations (pp. 33-47). Monterey, CA: Brooks/Cole.

Tenbrunsel, A. E., \& Messick, D. M. (1999). Sanctioning systems, decision frames, and cooperation. Administrative Science Quarterly, 44(4), 684-707. doi:10.2307/2667052.

Tenbrunsel, A. E., \& Smith-Crowe, K. (2008). Chapter 13: Ethical decision making: Where we've been and where we're going. Academy of Management Annals, 2(1), 545. doi:10.1080/ 19416520802211677.

Terry, D. J., \& Hogg, M. A. (1996). Group norms and the attitudebehavior relationship: a role for group identification. Personality and Social Psychology Bulletin, 22(8), 776-793. doi:10.1177/ 0146167296228002.

Tett, R. P., \& Burnett, D. D. (2003). A personality trait-based interactionist model of job performance. Journal of Applied Psychology, 88(3), 500-17. Retrieved from http://www.ncbi. nlm.nih.gov/pubmed/12814298

Trevino, L. K. (1986). Ethical decision making in organizations: A person-situation interactionist model. Academy of Management Review, 11(3), 601-617. doi:10.5465/AMR.1986.4306235.

Treviño, L. K., \& Weaver, G. R. (2001). Organizational justice and ethics program "Follow-Through": Influences on employees' harmful and helpful behavior. Business Ethics Quarterly, 11(4), 651-671. Retrieved from http://www.jstor.org/stable/3857765

Treviño, L. K., Weaver, G. R., \& Reynolds, S. J. (2006). Behavioral ethics in organizations: A review. Journal of Management, 32(6), 951-990. doi:10.1177/0149206306294258.

Turner, N., Hogg, M. A., Oakes, P. J., Reicher, S. D., \& Wetherell, M. S. (1987). Rediscovering the social group: A self-categorization theory. Oxford: Blackwell. 
Umphress, E. E., \& Bingham, J. B. (2011). When employees do bad things for good reasons: Examining unethical pro-organizational behaviors. Organization Science, 22(3), 621-640. doi:10.1287/ orsc. 1100.0559 .

Umphress, E. E., Bingham, J. B., \& Mitchell, M. S. (2010). Unethical behavior in the name of the company: The moderating effect of organizational identification and positive reciprocity beliefs on unethical pro-organizational behavior. Journal of Applied Psychology, 95(4), 769-780. doi:10.1037/a0019214.

Vadera, A. K., \& Pratt, M. G. (2012). Love, hate, ambivalence, or indifference? A conceptual examination of workplace crimes and organizational identification. Organization Science, 24(1), 172-188. doi:10.1287/orsc.1110.0714.

Van Dick, R., Christ, O., Stellmacher, J., Wagner, U., Ahlswede, O., Grubba, C., \& Hoehfeld, C. (2004). Should I stay or should I go? Explaining turnover intentions with organizational identification and job satisfaction. British Journal of Management, 15(4), $351-360$

Van Dick, R., Hirst, G., Grojean, M. W., \& Wieseke, J. (2007). Relationships between leader and follower organizational identification and implications for follower attitudes and behaviour. Journal of Occupational and Organizational Psychology, 80(1), 133-150. doi:10.1348/096317905X71831.

Van Gils, S., Van Quaquebeke, N., \& van Knippenberg, D. (2010). Tango in the dark: The interplay of leader's and follower's level of selfconstrual and its impact on ethical behavior in organizations. In T. Hansbrough \& B. Schyns (Eds.), When leadership goes wrong: Destructive leadership, mistakes and ethical failures (pp. 285-303). Greenwich, CT: Information Age Publishing.
Van Knippenberg, D., \& Hogg, M. A. (2003). A social identity model of leadership effectiveness in organizations. In R. M. Kramer \& B. M. Staw (Eds.), Research in organizational behavior (Vol. 25, pp. 243-295). Amsterdam: Elsevier. doi:10.1016/S01913085(03)25006-1.

Van Knippenberg, D., van Knippenberg, B., De Cremer, D., \& Hogg, M. A. (2004). Leadership, self, and identity: A review and research agenda. Leadership Quarterly, 15(6), 825-856. doi:10. 1016/j.leaqua.2004.09.002.

Victor, B., \& Cullen, J. B. (1988). The organizational bases of ethical work climates. Administrative Science Quarterly, 33(1), 101-125. doi:10.2307/2392857.

Walumbwa, F. O., Mayer, D. M., Wang, P., Wang, H., Workman, K., \& Christensen, A. L. (2011). Linking ethical leadership to employee performance: The roles of leader-member exchange, self-efficacy, and organizational identification. Organizational Behavior and Human Decision Processes, 115(2), 204-213. doi:10.1016/j.obhdp.2010.11.002.

Wellen, J. M., Hogg, M. A., \& Terry, D. J. (1998). Group norms and attitude-behavior consistency: The role of group salience and mood. Group Dynamics: Theory, Research, and Practice, 2(1), 48-56.

Wimbush, J. C., Shepard, J. M., \& Markham, S. E. (1997). An empirical examination of the relationship between ethical climate and ethical behavior from multiple levels of analysis. Journal of Business Ethics, 16(16), 1705-1716. doi:10.1023/A: 1017952221572.

Zhong, C.-B., Ku, G., Lount, R. B. J., \& Murninghan, J. K. (2010). Compensatory ethics. Journal of Business Ethics, 92, 323-339. 